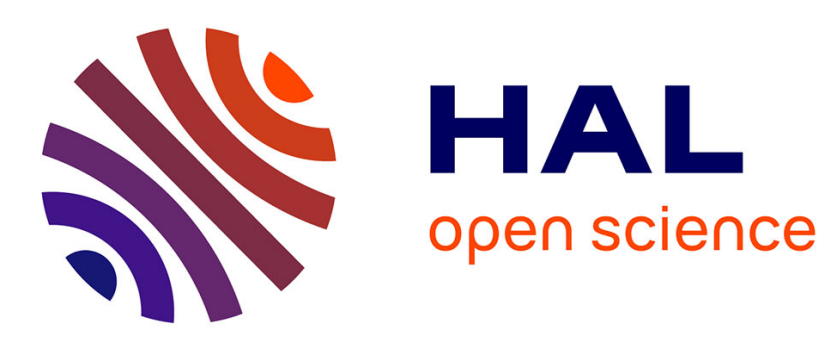

\title{
Spinal proerectile effect of oxytocin in anesthetized rats
}

\author{
F. Giuliano, Jacques Bernabé, K. Mckenna, F. Longueville, Olivier Rampin
}

\section{To cite this version:}

F. Giuliano, Jacques Bernabé, K. Mckenna, F. Longueville, Olivier Rampin. Spinal proerectile effect of oxytocin in anesthetized rats. AJP - Regulatory, Integrative and Comparative Physiology, 2001, 280, pp.R1870-R1877. hal-02674018

\section{HAL Id: hal-02674018 \\ https://hal.inrae.fr/hal-02674018}

Submitted on 31 May 2020

HAL is a multi-disciplinary open access archive for the deposit and dissemination of scientific research documents, whether they are published or not. The documents may come from teaching and research institutions in France or abroad, or from public or private research centers.
L'archive ouverte pluridisciplinaire HAL, est destinée au dépôt et à la diffusion de documents scientifiques de niveau recherche, publiés ou non, émanant des établissements d'enseignement et de recherche français ou étrangers, des laboratoires publics ou privés. 


\title{
Spinal proerectile effect of oxytocin in anesthetized rats
}

\author{
FRANÇOIS GIULIANO, ${ }^{1}$ JACQUES BERNABÉ, ${ }^{2}$ KEVIN MCKENNA, ${ }^{3}$ \\ FLORENCE LONGUEVILLE, ${ }^{1}$ AND OLIVIER RAMPIN ${ }^{2}$ \\ ${ }^{1}$ Groupe de Recherche en Urologie, UPRES EA1602, Faculté de Médecine Paris-Sud, 94270 \\ Le Kremlin Bicêtre; ${ }^{2}$ Laboratoire de Neurobiologie des Fonctions Végétatives, Bâtiment 325, \\ Institut National de la Recherche Agronomique, 78352 Jouy-en-Josas Cedex, France; and \\ ${ }^{3}$ Department Physiology, Northwestern University, Chicago, Illinois 60611
}

Received 11 October 2000; accepted in final form 6 February 2001

\begin{abstract}
Giuliano, François, Jacques Bernabé, Kevin McKenna, Florence Longueville, and Olivier Rampin. Spinal proerectile effect of oxytocin in anesthetized rats. Am J Physiol Regulatory Integrative Comp Physiol 280: R1870-R1877, 2001.-The spinal cord contains the neural network that controls penile erection. This network is activated by information from peripheral and supraspinal origin. We tested the hypothesis that oxytocin (OT), released at the lumbosacral spinal cord level by descending projections from the paraventricular nucleus, regulated penile erection. In anesthetized male rats, blood pressure and intracavernous pressure (ICP) were monitored. Intrathecal (it) injection of cumulative doses of $\mathrm{OT}$ and the selective OT agonist $\left[\mathrm{Thr}^{4}, \mathrm{Gly}^{7}\right] \mathrm{OT}$ at the lumbosacral level elicited ICP rises whose number, amplitude, and area were dose dependent. Thirty nanograms of OT and one-hundred nanograms of the agonist displayed the greatest proerectile effects. Single injections of OT also elicited ICP rises. Preliminary injection of a specific OT-receptor antagonist, hexamethonium, or bilateral pelvic nerve section impaired the effects of OT injected it. $\mathrm{NaCl}$ and vasopressin injected it at the lumbosacral level and OT injected it at the thoracolumbar level or intravenously had no effect on ICP. The results demonstrate that OT, acting at the lumbosacral spinal cord, elicits ICP rises in anesthetized rats. They suggest that OT, released on physiological activation of the PVN in a sexually relevant context, is a potent activator of spinal proerectile neurons.
\end{abstract}

urogenital; sexual reflexes; paraventricular nucleus

PHARMACOLOGICAL STIMULATION of the paraventricular nucleus of the hypothalamus (PVN), through a variety of neuroactive compounds in conscious rats and electrical or pharmacological stimulation of the PVN in anesthetized rats, elicits penile erection and intracavernous pressure (ICP) increases $(3,8)$. The PVN contributes descending oxytocinergic fibers to the spinal cord (7), and the paraventriculospinal tract originates in the parvocellular part of the PVN (15). In male rats, the lumbosacral spinal cord contains oxytocinergic fibers (29), some of which synapse onto spinal preganglionic neurons (30). Furthermore, specific oxytocin (OT) bind-

\footnotetext{
Address for reprint requests and other correspondence: F. Giuliano, Dept. Urology, CHU de Bicêtre, 78 rue du Général Leclerc, 94270 Le Kremlin Bicêtre, France (E-mail: giuliano@cyber-sante.
} org). ing sites are present in the sacral parasympathetic nucleus and the dorsal grey commissure of the L6-S1 spinal cord (34). Finally, PVN neurons are transsynaptically labeled with pseudorabies virus (PRV) injected in the corpus cavernosum (18). Engorgement of the penis with blood, leading to erection, is caused by increased blood flow to the penis and active relaxation of the erectile tissue of the corpora cavernosa and the corpus spongiosum (1). Both mechanisms are controlled by the autonomic nervous system. In rats, the sympathetic outflow to the penis originates in the T12-L2 spinal cord, and the proerectile parasympathetic outflow originates in the L6-S1 spinal cord (9). The sacral parasympathetic nucleus (SPN) of the L6-S1 spinal cord contains the preganglionic neurons that innervate the pelvic organs, including the penis. In a sexually relevant context, activation of proerectile neurons in the SPN may be elicited by information from peripheral or supraspinal origins (24). We tested the hypothesis that OT released by paraventriculospinal pathways could regulate the spinal control of penile erection through an effect on lumbosacral neurons in the rat.

\section{MATERIAL AND METHODS}

Animals. Adult male Sprague-Dawley rats, sexually naïve and weighing 200-250 g, were purchased from Charles River (Saint-Aubin les Elbeufs, France). Rats were housed in groups of four in plastic cages containing wood-chip bedding. They had free access to commercial pelleted rodent chow (Piètrement, Provins, France) and tap water. Cages were placed in an animal facility maintained at $20^{\circ} \mathrm{C}$ and kept in a 12:12-h light-dark cycle (lights on at 8 AM). All animal experiments were carried out in accordance with the European Economical Community Directive of November 24, 1986 (86/609/EEC) on the use of laboratory animals. All efforts were made to minimize animal suffering and to reduce the number of animals used.

Experimental procedure. Rats were anesthetized with an intraperitoneal injection of urethane $(1.2 \mathrm{~g} / \mathrm{kg}$ in sterile water), and their temperature was maintained at $37^{\circ} \mathrm{C}$ using a

\footnotetext{
The costs of publication of this article were defrayed in part by the payment of page charges. The article must therefore be hereby marked "advertisement" in accordance with 18 U.S.C. Section 1734 solely to indicate this fact.
} 
homeothermic blanket. Intrathecal (it) catheterization was performed as reported by LoPachin et al. (17). Briefly, the rat's head was placed in a stereotaxic frame and was rotated nose downwards to facilitate catheter insertion. The catheter, a polyethylene tubing (PE-10) stretched to $150 \%$ of its original length in hot water, was cut to the required length so that its distal opening reached the L4-L6 or T12-T13 levels of the spinal cord. The skin and neck muscles were incised and retracted. The atlantooccipital membrane was opened, and the catheter, flushed with sterile $\mathrm{NaCl} 0.9 \%$, was carefully advanced in the caudal direction. Finally, the rostral free end of the catheter was secured with the ligatures that closed the neck muscles and skin layers. The catheter was connected to a Hamilton syringe filled with saline to prevent cerebrospinal fluid leakage. Rats were tracheotomized to prevent aspiration of saliva and to perform artificial ventilation when muscle relaxant was used. The carotid artery and jugular vein were catheterized with polyethylene tubings filled with heparinized saline $(25 \mathrm{U} / \mathrm{ml})$ to record blood pressure $(\mathrm{BP})$ via a pressure transducer (Elcomatic 750, Glasgow, UK) and inject drugs intravenously, respectively. ICP recording was performed as described previously (12). Tables 1 and 3 display the different groups of rats that we used. For it injections, compounds dissolved in $10 \mu \mathrm{l}$ of $\mathrm{NaCl} 0.9 \%$ were injected within 10-20 s, immediately followed by a flush of $10 \mu \mathrm{l} \mathrm{NaCl}$ $0.9 \%$. When we used cumulative injections of drugs, two consecutive injections were separated by a 15 -min period. To perform pelvic nerve section (PNx rats), a suprapubic incision was performed. The pelvic nerves were exposed at the lateral aspect of the prostate, and nerves were sectioned 2-3 $\mathrm{mm}$ proximal to the major pelvic ganglion.

At the end of all experiments, rats were killed with an intravenous (iv) overdose of urethane. Ten microliters of methylene blue were injected it and flushed with $10 \mu \mathrm{l}$ of $\mathrm{NaCl} 0.9 \%$. The spinal cord was then exposed, and the exact location of the caudal tip of the catheter was carefully noted. Only rats with a catheter tip located either at the L4-L6 or at the T12-T13 level of the spinal cord were considered for the results. Diffusion of methylene blue from the tip of the catheter revealed that spinal levels exposed to the injected drugs extended approximately one segment rostral to one segment caudal to the segment facing the tip of the catheter.

Data analysis. ICP rises were detected as increases in ICP pressure above a threshold. This threshold was calculated as the ICP value averaged over the 15-min period of observation before drug injection plus two standard deviations. The number of rats that displayed at least one ICP rise during the experiment, the number of ICP rises per rat averaged for each group, the number of ICP rises occurring within each period of 15 min separating two consecutive injections, the latency of the first ICP, and the duration of ICP rises were calculated. There exists a strong positive correlation between the amplitude of ICP increase elicited by cavernous nerve stimulation and BP (12). Therefore, in the present experiment, the amplitude of each ICP increase was reported to the corresponding diastolic $\mathrm{BP}$ (the ICP/BP ratio) (13). If several $\mathrm{ICP}$ rises occurred within the 15 -min period separating two injections, then we averaged the ICP/BP ratio over the number of ICP rises. The area under the curve (AUC), also relative to diastolic $\mathrm{BP}$ and integrated over each 15-min period, was calculated. Where appropriate, results are expressed as mean values $\pm \mathrm{SE}$. Variables were evaluated by ANOVA followed by multiple-comparisons tests. Differences were considered statistically significant at $P<0.05$.

Drugs. Urethane, OT, the OT agonist $\left[\mathrm{Thr}^{4}, \mathrm{Gly}^{7}\right] \mathrm{OT}$, $\left[\mathrm{Arg}^{8}\right]$ vasopressin (AVP), and hexamethonium (HXM) were purchased from Sigma (Saint-Quentin-Fallavier, France) and dissolved to the required concentration in $\mathrm{NaCl} 0.9 \%$. Gallamine triethiodide (Flaxedil) was purchased from Specia (Rhône-Poulenc Rorer, Paris, France). The OT antagonist $\left[(\mathrm{S}) \mathrm{PMP}^{1}, \mathrm{D}-\mathrm{Trp}^{2}, \mathrm{Pen}^{6}, \mathrm{Arg}^{8}\right] \mathrm{OT}$ was a generous gift from Dr. G. Flouret (Northwestern Univ., Chicago, IL).

\section{RESULTS}

Cumulative injections of OT. Injection (it) of OT elicited ICP rises (Fig. $1 A$ ). Table 2 displays the number of rats, named responders, that had at least one ICP rise during the recording. Kruskal-Wallis one-way ANOVA on ranks demonstrated that there was a treatment effect on the number of responders $(H=41.8$, $\mathrm{df}=9, P=3.6 \times 10^{-6}$ ). At least one ICP rise was recorded after injection of $\mathrm{NaCl}, \mathrm{OT}$ at the L4-L6 and at the T12-T3 levels, OT iv, OT agonist (Fig. 1B), and OT at the L4-L6 level after curarization. In contrast, the groups that received injection of the OT antagonist followed by OT at the L4-L6 level, AVP, OT at the L4-L6 level after PNx, or HXM $(P<0.05$ for each) included significantly fewer or no responders. Therefore, the effects of OT were impaired by the OT antagonist (Fig. 1C) by lesioning preganglionic fibers conveyed by the pelvic nerve and by blocking the transmission between pre- and postganglionic neurons. AVP had no effect on ICP.

To further search for differences between groups of responders, we analyzed the number of ICP rises per

Table 1. Effects of drugs, injected either it or iv, on intracavernous pressure of anesthetized male rats

\begin{tabular}{|c|c|c|c|}
\hline Drug & Route/Site & Dose & Number of Rats \\
\hline $\mathrm{NaCl}(0.9 \%)$ & it L4-L6 & 8 injections & 10 \\
\hline OT & it L4-L6 & $0.3,1,3,10,30,100$, and $300 \mathrm{ng}$ & 10 \\
\hline OT & it $\mathrm{T} 12-\mathrm{T} 13$ & $0.3,1,3,10,30,100$, and $300 \mathrm{ng}$ & 10 \\
\hline OT & iv & $0.3,1,3,10,30,100$, and $300 \mathrm{ng}$ & 8 \\
\hline$\left[\mathrm{Thr}^{4}, \mathrm{Gly}^{7}\right] \mathrm{OT}$ & it L4-L6 & $0.3,1,3,10,30,100$, and $300 \mathrm{ng}$ & 8 \\
\hline AVP & it L4-L6 & $0.3,1,3,10,30,100$, and $300 \mathrm{ng}$ & 8 \\
\hline$\left[(\mathrm{S}) \mathrm{PMP}^{1}\right.$, D-Trp $\left.{ }^{2}, \mathrm{Pen}^{6}, \mathrm{Arg}^{8}\right] \mathrm{OT}$ & it L4-L6 & $100 \mathrm{ng}^{*}$ & 8 \\
\hline $\mathrm{PNx}$ & & $*$ & 8 \\
\hline HMX & iv & $60 \mathrm{mg} / \mathrm{kg}^{*}$ & 5 \\
\hline Gallamine triethiodide & iv & $30 \mathrm{mg} / \mathrm{kg} *$ & 5 \\
\hline
\end{tabular}

$\mathrm{NaCl}(0.9 \%)$, sodium chloride; OT, oxytocin; [Thr ${ }^{4}$, Gly]OT, oxytocin agonist; [(S)PMP $\left.{ }^{1}, \mathrm{D}^{-T_{r p}}{ }^{2}, \mathrm{Pen}^{6}, \mathrm{Arg}^{8}\right] \mathrm{OT}^{\mathrm{O}}$, oxytocin antagonist; AVP, $\left[\mathrm{Arg}^{8}\right]$ vasopressin; HMX, hexamethonium, nicotinic receptors antagonist; gallamine triethiodide, striated muscle relaxant; PNx, bilateral section of the pelvic nerve; iv, intravenously. *Before cumulative doses of OT intrathecally (it) delivered at the L4-L6 level. 
Fig. 1. Three recordings of blood pressure (BP; top traces) and intracavernous pressure (ICP; bottom traces; in $\mathrm{mmHg}$ ) in 3 different anesthetized male rats. $A$ : intrathecal injection of $0.9 \% \mathrm{NaCl}$ (at $t=0 \mathrm{~min}$ ), then each $15 \mathrm{~min}$, increasing doses of oxytocin (OT; 0.3 , $1,3,10,30,100$, and $300 \mathrm{ng}$ ) were injected by the same route. $B$ : same as $A$, but injection of the OT agonist $\left[\mathrm{Thr}^{4}, \mathrm{Gly}^{7}\right] \mathrm{OT}$ was performed. $C$ : at $t=15$ min, injection of the OT antagonist $\left[\left(\mathrm{S}^{2} \mathrm{PMP}^{1}, \mathrm{D}-\right.\right.$ $\operatorname{Trp}^{2}, \mathrm{Pen}^{6}, \mathrm{Arg}^{8}$ OT was performed, then same doses of OT as in $A$.
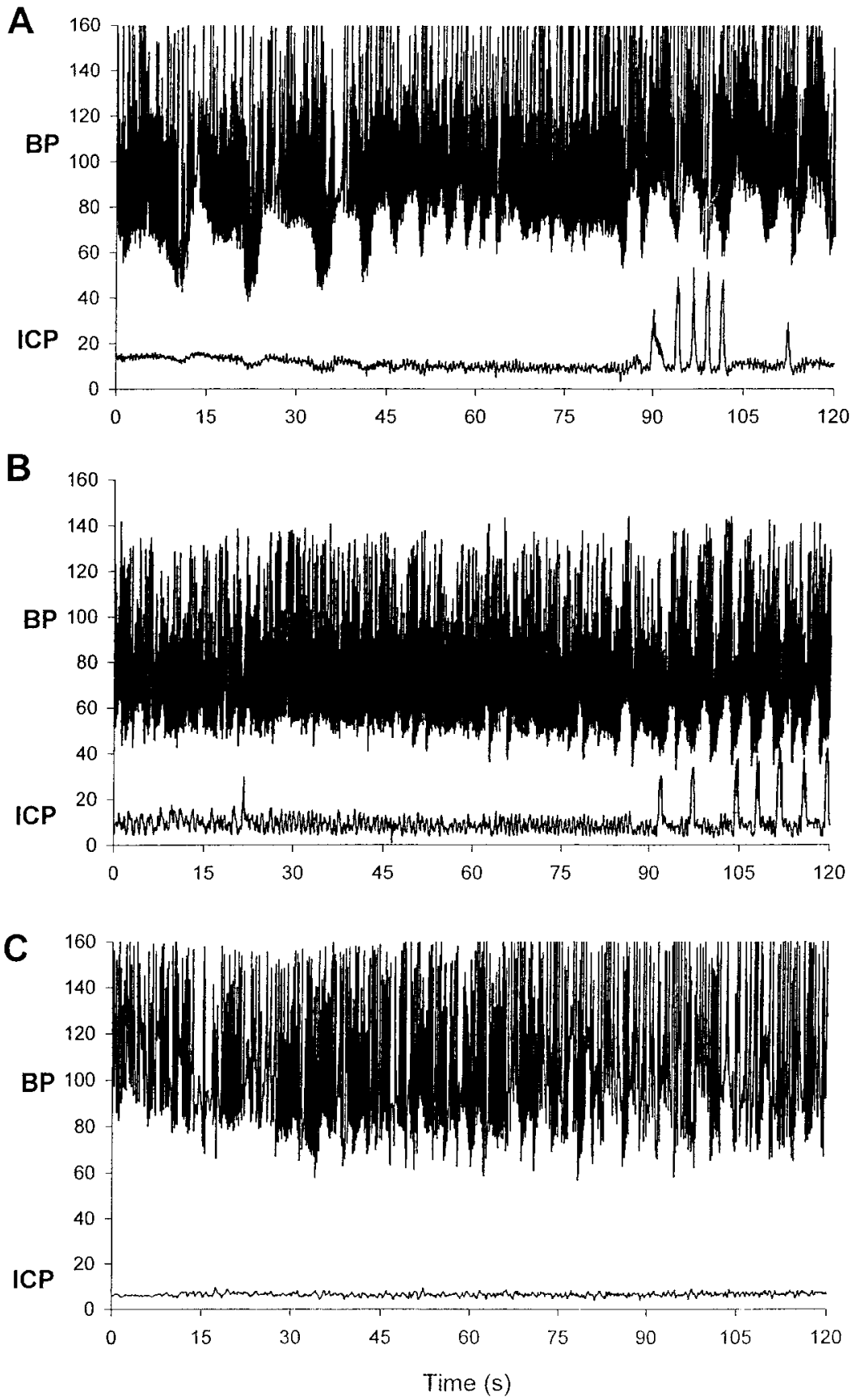

group (Table 2). Kruskal-Wallis one-way ANOVA on ranks demonstrated that there was a treatment effect on the number of ICP rises $(H=41.5, \mathrm{df}=9, P=$ $\left.4.1 \times 10^{-6}\right)$. Rats that received it injection of $\mathrm{NaCl}$ at the L4-L6 level, OT iv, and OT it at the T12-T13 level significantly displayed fewer ICP rises than rats treated with OT it at the L4-L6 level, the OT agonist it at the L4-L6 level, or OT it at the L4-L6 level after curarization $(P<0.05$ for each). In contrast, there was no significant difference among the last three groups.

We also searched for a dose effect of OT or its agonist on the total number of ICP rises (Fig. 2). The response curve of the it OT L4-L6 group was bell shaped (Fig. 2).
In this group, there was a statistically significant effect of the dose of OT injected on the number of ICP rises (Friedman repeated-measures ANOVA on ranks, $\chi^{2}=$ 38.8 , df $=7, P=2.0 \times 10^{-6}$ ). Ten and thirty nanograms of OT elicited significantly more ICP rises than the other doses $(P<0.05$ for each). In the group treated with the OT agonist delivered it at the L4-L6 level, the dose effect was also present (Friedman repeated-measures ANOVA on ranks, $\chi^{2}=27.8, \mathrm{df}=7, P=2.0 \times$ $10^{-4}$ ), but the greatest doses used elicited the greatest number of ICP rises. One-hundred nanograms of the OT agonist elicited significantly more ICP rises than vehicle $0.3,1,3$, and $10 \mathrm{ng}(P<0.05$ for each). Threehundred nanograms of the OT agonist elicited signifi- 
Table 2. Effects of it and iv injections of OT and other drugs 1) on the number of rats that displayed at least one ICP rise during the experiment (responders) relative to $N$ and 2) on the number of ICP rises per rat in each group

\begin{tabular}{lccc}
\hline \hline \multicolumn{1}{c}{ Drug } & Route/Site & Responders/N & $\begin{array}{c}\text { Number of ICP } \\
\text { Rises/Rat }\end{array}$ \\
\hline $\mathrm{NaCl}(0.9 \%)$ & it L4-L6 & $8 / 10$ & $2 \pm 2$ \\
$\mathrm{OT}$ & it L4-L6 & $10 / 10$ & $7 \pm 4$ \\
$\mathrm{OT}$ & it T12-T13 & $6 / 10$ & $2 \pm 2^{*}$ \\
$\mathrm{OT}$ & iv & $6 / 8$ & $3 \pm 3^{*}$ \\
[Thr $\left.{ }^{4}, \mathrm{Gly}^{7}\right] \mathrm{OT}$ & it L4-L6 & $8 / 8$ & $6 \pm 3$ \\
[(S)PMP $\mathrm{PM}^{1}, \mathrm{Drp}{ }^{2}$, & & & \\
$\left.\mathrm{Pen}{ }^{6}, \mathrm{Arg}^{8}\right] \mathrm{OT}$ & it L4-L6 & $1 / 8^{*}$ & $1 \pm 2^{*}$ \\
$\mathrm{AVP}$ & it L4-L6 & $1 / 8^{*}$ & $1 \pm 1^{*}$ \\
$\mathrm{PNx}$ & & $1 / 8^{*}$ & $1 \pm 1^{*}$ \\
$\mathrm{HMX}$ & iv & $0 / 5^{*}$ & $0 *$ \\
Gallamine & & & \\
triethiodide & iv & $3 / 5$ & $9 \pm 10$ \\
\hline
\end{tabular}

$\mathrm{N}$, no. of rats in each group; ICP, intracavernous pressure. * Statistically different from OT delivered it at the L4-L6 level $(P<0.05)$. No. of ICP rises/rat are means \pm SE.

cantly more ICP rises than vehicle $0.3,1$, and $3 \mathrm{ng}(P<$ 0.05 for each).

Comparing the effects of OT and its agonist, $10 \mathrm{ng}$ of OT elicited a greater number of ICP rises than $10 \mathrm{ng}$ of the agonist $(P=0.0321)$. No difference in the number of ICP rises occurred at 30 and $100 \mathrm{ng}$ between OT and its agonist $(P=0.0548$ and $P=0.1584$, respectively). Finally, $300 \mathrm{ng}$ of the OT agonist elicited more ICP rises than $300 \mathrm{ng}$ of OT $(P=0.0084)$.

We further measured the effects of OT and its agonist on the amplitude of the ICP rises, expressed as the ICP/BP ratio (Fig. 3). When ICP reached $40-60 \mathrm{mmHg}$, we could observe a vascular engorgement of the penis. One-way ANOVA revealed that there was a dose effect of OT on ICP/BP $\left[F(9,79)=7.91, P=7.0 \times 10^{-7}\right]$. OT (10, 30, and $100 \mathrm{ng})$ elicited ICP/BP greater than vehi-

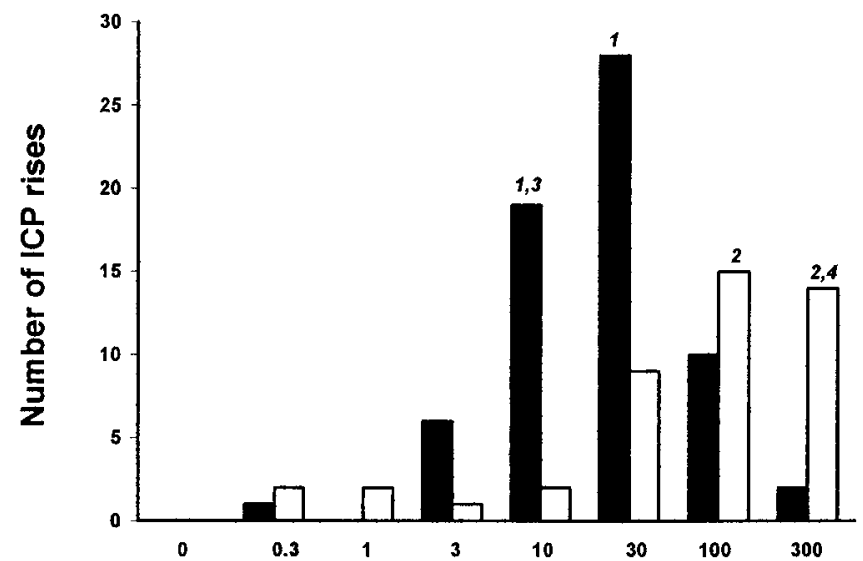

Fig. 2. Effects of OT (filled bars) and the OT agonist $\left[\mathrm{Thr}^{4}, \mathrm{Gly}^{7}\right] \mathrm{OT}$ (open bars) delivered intrathecally, cumulative doses (0-300 ng), on the number of ICP rises recorded in anesthetized male rats. OT (10 and $30 \mathrm{ng}$ ) elicited more ICP rises than the other doses $(P<0.05 ; 1)$. OT agonist (100 and $300 \mathrm{ng}$ ) elicited more ICP rises than the other doses $(P<0.05 ; 2)$. OT $(10 \mathrm{ng})$ elicited more ICP rises than $10 \mathrm{ng}$ of the OT agonist $(P<0.05 ; 3)$. OT agonist (300 ng) elicited more ICP rises than $300 \mathrm{ng}$ of OT $(P<0.05 ; 4)$.

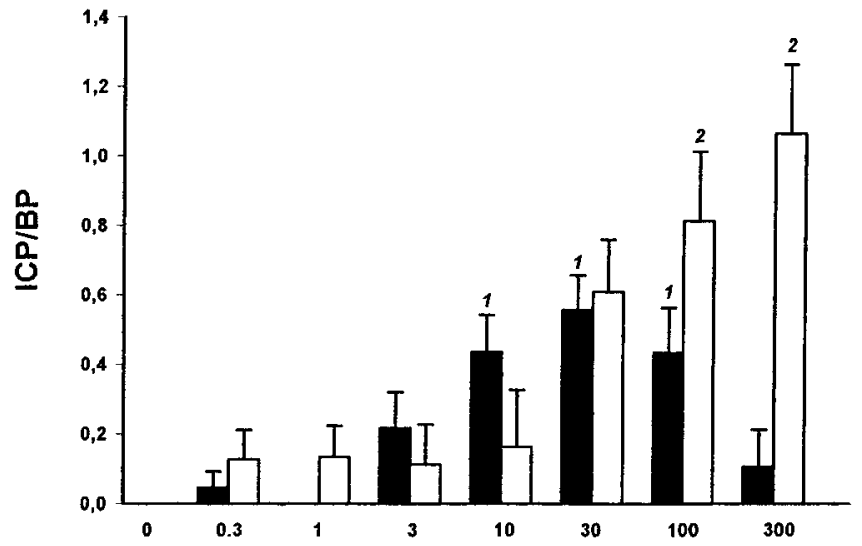

Fig. 3. Effects of OT (filled bars) and the OT agonist $\left[\mathrm{Thr}^{4}, \mathrm{Gly}^{7}\right] \mathrm{OT}$ (open bars) delivered intrathecally, cumulative doses (0-300 ng), on the ICP/BP ratio. OT $(10,30$, and $100 \mathrm{ng})$ elicited the greatest ICP rises as measured by the ratio $\operatorname{ICP} / \mathrm{BP}(P<0.05 ; 1)$. OT agonist $(100$ and $300 \mathrm{ng})$ elicited the greatest ICP rises $(P<0.05 ; 2)$.

cle $(0.3,1$, and $300 \mathrm{ng} ; P<0.05$ for each). No difference was found among 10, 30, and $100 \mathrm{ng}$ OT. There was also a dose effect of the OT agonist on ICP/BP: $\chi^{2}$ for this group was $35.5\left(\mathrm{df}=7, P=9 \times 10^{-6}\right)$. Onehundred and three-hundred nanograms of the OT agonist elicited ICP/BP significantly greater than those elicited by the other doses $(P<0.05$ for each), and 300 ng elicited greater responses than $100 \mathrm{ng}(P<0.05)$.

Furthermore, there was a dose effect of OT injections on the AUC of the ICP rise, expressed by the AUC/BP ratio (Fig. $\left.4 ; \chi^{2}=34.0, \mathrm{df}=7, P=1.6 \times 10^{-5}\right)$. OT $(10$ and $30 \mathrm{ng}$ ) elicited significantly greater AUC/BP than the other doses $(P<0.05$ for each). In contrast, there was no difference between 10 and $30 \mathrm{ng}$ OT. The OT agonist also yielded a significant dose effect on AUC/BP $\left[F(7,63)=7.81, P=2.5 \times 10^{-6}\right]$. One-hundred and three-hundred nanograms of the OT agonist yielded a significantly greater AUC/BP than the other doses $(P<0.05$ for each), although there was no dif-

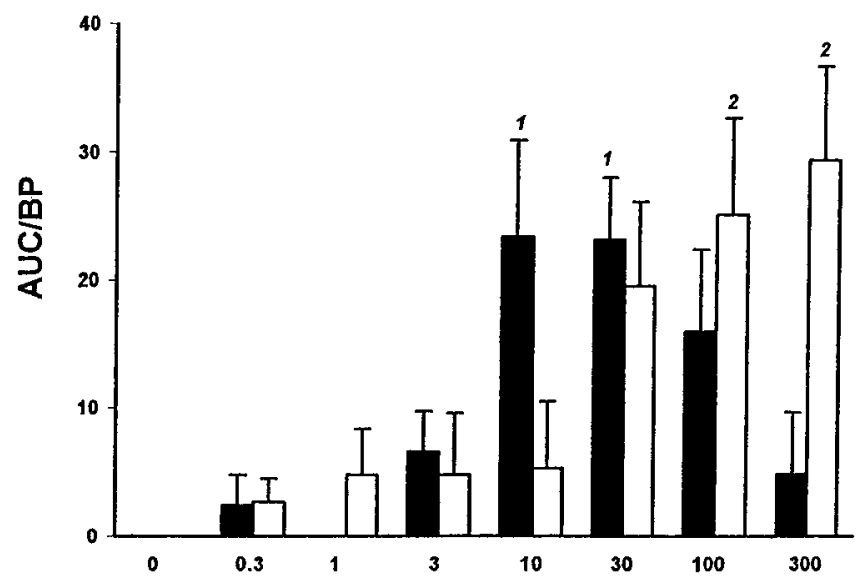

Fig. 4. Effects of OT (filled bars) and the OT agonist $\left[\mathrm{Thr}^{4}, \mathrm{Gly}^{7}\right] \mathrm{OT}$ (open bars) delivered intrathecally, cumulative doses (0-300 ng), on the area under the curve (AUC) of ICP rises expressed by the AUC/BP ratio (arbitrary units). OT (10 and $30 \mathrm{ng}$ ) elicited the greatest AUC/BP $(P<0.05 ; 1)$. OT agonist (100 and $300 \mathrm{ng}$ ) elicited the greatest $\mathrm{AUC} / \mathrm{BP}(P<0.05 ; 2)$. 


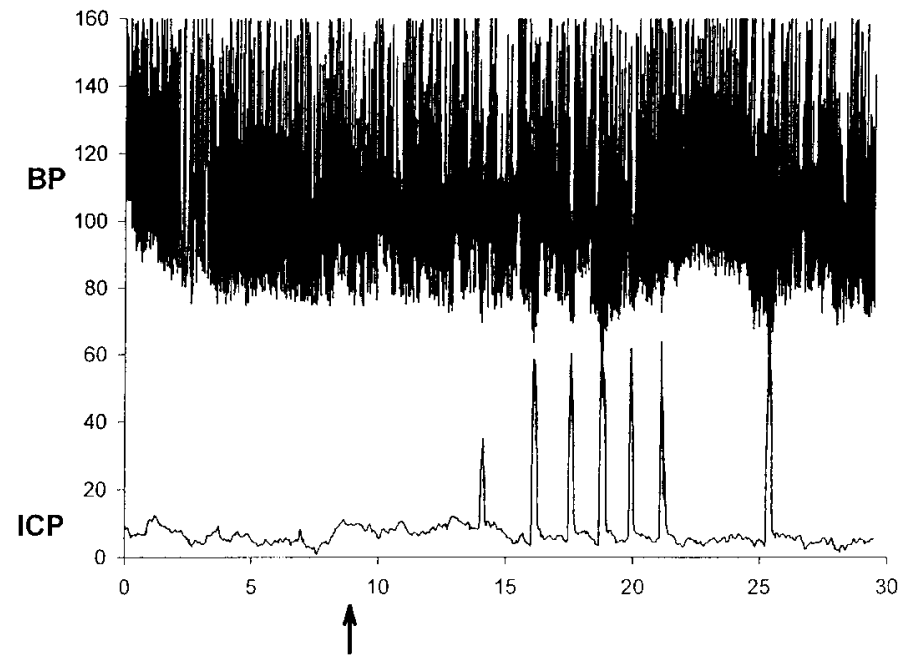

Fig. 5. Recording of BP (top trace) and ICP (bottom trace; in $\mathrm{mmHg}$ ) in 1 anesthetized male rat after the intrathecal injection of $0.9 \%$ $\mathrm{NaCl}$ (at $t=0 \mathrm{~min}$ ), then a single dose of $30 \mathrm{ng} \mathrm{OT}$ (arrow).

ference between 100 and 300 ng nor between 100 and $30 \mathrm{ng}$.

Injection of a single dose of OT. In a second group of experiments, we tested whether single injections of OT elicited ICP rises, based on a 30-min period of observation after injection (Fig. 5, Table 3). There was a significant dose effect of OT on the number of responders $(H=8.77, \mathrm{df}=3, P=0.0326)$. The group that received $300 \mathrm{ng}$ OT included significantly less responders ( 2 of 8 ) than the other groups (Table 3,2 nd column). Conversely, there was no dose effect of OT on the number of ICP rises $[F(3,33)=2.08, P=0.1240]$. Neither latency to the first ICP rise nor duration of ICP rises was dependent on the dose injected $\{[F(3,21)=$ $0.471, P=0.7062]$ and $[F(3,21)=2.24, P=0.1184$, respectively]\}. Finally, neither the ICP/BP nor the AUC/BP ratio was dependent on the doses injected $(H=3.73, \mathrm{df}=3, P=0.292$ and $H=7.64, \mathrm{df}=3, P=$ 0.0540 , respectively).

\section{DISCUSSION}

Results of the present study provide evidence for a proerectile effect of OT at the lumbosacral level in anesthetized rats. Delivering OT intravenously had no effect on ICP. OT receptors are present in the reproductive tract of males (11). OT contracts smooth mus- cles of the genital tract in vivo (20) and contracts the corpus cavernosum in vitro (32). Therefore, one cannot expect a proerectile (relaxant) effect of OT through an effect on a peripheral target.

Delivering OT at the T12-T13 level had no reliable effects on ICP. The thoracolumbar spinal cord contains sympathetic neurons destined to the penis (18). These sympathetic pathways are classically considered antierectile. Therefore, even if OT activated these neurons, the consequence could not be an erection. Proerectile effects should therefore be attributed to a specific targeting of OT on the lumbosacral spinal cord.

This hypothesis was confirmed by the fact that only rats that received OT at the lumbosacral level displayed the greatest number of ICP rises. We performed additional experiments to demonstrate that proerectile effects were OT specific. Only rats that received OT or its specific agonist, $\left[\mathrm{Thr}^{4}, \mathrm{Gly}^{7}\right] \mathrm{OT}$, reliably displayed ICP rises. Vasopressin did not elicit such a response. Therefore, ICP rises were elicited by OT and not vasopressin. The presence of ICP rises occurring on it $\mathrm{NaCl}$ are likely spontaneous events. Their number is not constant between rats or the rank of injection. However, it suggests that erection may occur spontaneously under anesthesia in rats. After injections of the OT antagonist $\left[(\mathrm{S}) \mathrm{PMP}^{1}, \mathrm{D}-\mathrm{Trp}^{2}, \mathrm{Pen}^{6}, \mathrm{Arg}^{8}\right] \mathrm{OT}$, followed by OT, ICP rises were only recorded in one rat. It is unclear whether the ICP rises in this animal could be considered spontaneous. In this rat, we numbered two and three ICP rises in response to 100 and $300 \mathrm{ng}$ OT, respectively. We hypothesize that in this animal, the dose of OT antagonist was not great enough to prevent responses to high doses of OT. We also consider that in the one rat that displayed ICP rises after vasopressin injection, such ICP rises occurred spontaneously. Indeed, they were recorded after an injection of $0.3 \mathrm{ng}$ vasopressin. When compared with other groups, neither $0.3 \mathrm{ng}$ OT nor its agonist elicited ICP rises.

After it injections of $30 \mathrm{ng} \mathrm{OT}$, the number of ICP rises, their amplitude, and area were greater than those recorded with the other OT doses. After it injections of the OT agonist, 100 and $300 \mathrm{ng}$ elicited the greatest numbers of ICP rises, and these reached the greatest amplitudes. The bell-shaped curve was evident when using OT, and rare or no ICP rises were recorded after $300 \mathrm{ng}$ OT. In contrast, $300 \mathrm{ng}$ of the OT agonist still elicited many responses. OT and $\left[\mathrm{Thr}^{4}, \mathrm{Gly}^{7}\right] \mathrm{OT}$ display the same affinity for the OT

Table 3. Effect of a single it injection of OT at the L4-L6 spinal cord on 1) the number of rats that displayed at least one ICP rise during the experiment (responders) relative to $N, 2$ ) the number of ICP rises per rat in each group, 3) the latency of the first ICP rise (s), 4) the duration of ICP rises (s), 5) the amplitude of ICP rises (ICP/BP ratio), and 6) the AUC of ICP rises (arbitrary units)

\begin{tabular}{cccccc}
\hline \hline Doses, $\mathrm{ng}$ & Responders/N & Number of ICP & Latency & Duration & ICP/BP \\
\hline 10 & $9 / 12$ & $4.4 \pm 1.3$ & $597 \pm 149$ & $75 \pm 8.0$ & $0.70 \pm 0.050$ \\
30 & $6 / 7$ & $4.9 \pm 1.4$ & $696 \pm 202$ & $65 \pm 7.0$ & $0.68 \pm .010$ \\
100 & $6 / 7$ & $4.7 \pm 1.0$ & $422 \pm 129$ & $90 \pm 9.0$ & $0.75 \pm 0.1$ \\
300 & $2 / 8 *$ & $1.0 \pm 0.7$ & $507 \pm 216$ & $52 \pm 2.0$ & $0.44 \pm 0.03$ \\
\hline
\end{tabular}

Values are means \pm SE. BP, blood pressure; AUC, area under the curve. * Statistically different from the other doses. 
receptor present in uterine smooth muscle (2); a difference between spinal and peripheral OT receptors could explain why $300 \mathrm{ng}$ OT does not elicit any erectile response in our experiment. It is unlikely that the saturability of the OT receptor accounts for the lack of ICP rises on $300 \mathrm{ng} \mathrm{OT}$, because this dose should elicit at least as many ICP rises as $100 \mathrm{ng}$ OT. It is interesting to note that $300 \mathrm{ng}$ OT elicited no more ICP rises when injected as either cumulative or single doses. Could the desensitization of the OT receptor explain this decrease of ICP response? In cultured astrocytes, OT applications elicited calcium rises in which amplitude decreased if the application was repeated. The authors observed a 20-min wash period between two applications before they could record a full recovery of the calcium response (10). In our experiment, a period of 15 min separated two consecutive injections, which suggests that no recovery could occur in this condition. OT $(10,30$, and $100 \mathrm{ng})$ elicited fewer ICPs on single doses compared with cumulative doses. Furthermore, the ICP/BP ratio displayed a bell-shaped response curve for cumulative treatments, but no such profile was noted on single-dose treatments. It remains unclear to us whether such differences rely on time of exposure of the receptor to OT or to an interaction between time of exposure and dose.

At high doses, OT may bind vasopressin receptors. The latter are present in the lumbosacral spinal cord of rats (33). Although 10 times less potent than vasopressin, OT could act on the $\mathrm{V}_{1}$ receptor of sympathetic preganglionic neurones of the neonate rat spinal cord (27). In our experiment, OT acting at vasopressin receptors could display inhibitory effects on spinal proerectile neurons. We tested the effects of it vasopressin. The peptide had no effect on ICP. In contrast, it could oppose a proerectile effect of OT.

SPN neurons convey parasympathetic fibers to the penis through the pelvic and cavernous nerves $(14,18$, $21)$. Electrical stimulation of the pelvic and cavernous nerves elicits ICP rises in anesthetized rats $(12,13$, 28). By delivering HXM iv, we blocked nicotinic receptors, thereby inhibiting the synaptic transmission between preganglionic fibers of the pelvic nerve and postganglionic fibers in the cavernous nerve. After HXM injection, no ICP rise occurred in response to it OT, demonstrating that OT recruited preganglionic neurons. The bilateral section of the pelvic nerve also prevented any ICP increase to occur after OT injection. Therefore, in the present study, the proerectile effects of OT are caused by activation of the sacral parasympathetic outflow. However, oxytocinergic activation of sacral parasympathetic pathways may be direct or relayed through interneurons present in the dorsal grey commissure of the lumbosacral spinal cord. Tight anatomic relationships between the two areas in the rat spinal cord, as demonstrated with transsynaptic transport of PRV from the corpus cavernosum, confirm this hypothesis (18). Furthermore, both areas contain OT receptors (34). Therefore, OT released by descending PVN-spinal pathways may activate both interneurons and preganglionic neurons.
Penile erection in conscious mammals recruits autonomic pathways to the penis and somatic pathways to the perineal striated muscles (25). In conscious mammals, contraction of striated muscles on the erect penis elicits peaks of penile pressure rises that largely override $\mathrm{BP}(5,23,26)$. According to some authors, bulbospongiosus (BS) and ischiocavernosus (IC) motoneurons receive descending projections from the PVN (35). Furthermore, transsynaptic retrograde labeling from the IC or BS muscles using PRV or rabies virus labels some neurons in the PVN $(19,31)$. According to these data, OT could also control the somatic outflow to the perineal striated muscles. However, although rare OTimmunoreactive fibers have been demonstrated in the ventral horn of the rat spinal cord $(30,34)$, this area does not contain OT receptors (34). After OT injection, we never recorded ICP rises over $\mathrm{BP}$, and the injection of the striated muscle blocking agent gallamine triethiodide did not affect the ICP rises elicited by OT. Therefore, our data demonstrate an effect of OT on penile pressure, independent of striated muscle, and suggest a lack of excitatory effect of OT onto IC and BS motoneurons.

OT may activate lumbosacral parasympathetic neurons and interneurons destined to pelvic organs other than the penis. Indeed, it was demonstrated that in conscious female rats, it OT increased micturition pressure and decreased bladder capacity and micturition volume (22). Interestingly, the most efficient dose in this model was $30 \mathrm{ng}$ OT. We also identified $30 \mathrm{ng}$ as the dose of OT that yielded the greatest probability of eliciting ICP rises when injected in cumulative doses, and only the number of responders when OT was injected as single doses. If comparable doses of OT activate different parasympathetic outflows, then it remains to be determined how the spinal network integrates this increase of OT, because all pelvic viscera are not active at the same time. It may be suggested that in a sexually relevant context, it is the convergence of information from the periphery and from supraspinal structures that elicits the specific activation of proerectile pathways at the spinal cord level.

In conscious rats, noncontact erections and druginduced erections (e.g., apomorphine-induced erections) reflect the activity of supraspinal nuclei. These erections are transient and repetitive, and recording ICP during noncontact and apomorphine-induced erections revealed transient rises of ICP (6). In our experiments, it injections of OT elicited phasic ICP rises. It suggests that the spinal cord translates the tonic excitation by supraspinal nuclei or by OT into the phasic activation of parasympathetic pathways leading to phasic ICP rises.

In our experiment, OT would be a potent activator of the spinal generator of penile erection. Once this rhythmic generator is activated, OT could not further regulate the number, the amplitude, and the area of the ICP rises, as evidenced by lack of dose effect of OT injection on the ICP/BP and AUC/BP ratios. 
Pharmacological stimulation of the PVN in conscious rats and its electrical stimulation in anesthetized rats elicit penile erection $(4,8)$. Lesions of the PVN suppress apomorphine-induced erections (4) and impair noncontact erections (16). In rats, fibers issued from the parvocellular part of the PVN reach the lumbosacral spinal cord (7). The SPN contains OT-immunoreactive fibers and OT receptors $(30,34)$. Our results suggest that by delivering OT at the lumbosacral level, we mimicked the release of OT by PVN-spinal fibers in rats. The present results demonstrate that OT exerts proerectile effects, as measured through increases in ICP, when it is delivered at the L4-L6 spinal cord in anesthetized rats. They demonstrate that the effects are specific, being mimicked by a specific agonist but not by arginine-vasopressin, and are blocked by a specific OT antagonist. Proerectile effects of OT are due to the activation of autonomic efferent pathways running in the pelvic nerves.

\section{Perspectives}

Our experiments suggest that the lumbosacral spinal cord is the final target of a proerectile, ocytocinergic pathway in which perikarya are in the parvocellular part of the PVN. This pathway represents a very efficient and direct proerectile link between supraspinal nuclei and the spinal cord. To better understand the contribution of peripheral and supraspinal information to the generation of erection, it is tempting to test the effects of OT in rats after a complete section of the spinal cord at the thoracic level, i.e., the interruption of the proerectile PVN-spinal pathway. Also, the comparison of the responses of the spinal cord to OT after a section that would be performed either immediately or several days before the test would provide an understanding of the strategies that some spinal networks can use to compensate for the lack of supraspinal information.

The authors gratefully acknowledge S. Compagnie, F. Derdinger, and R. Monnerie for technical contributions.

This work was supported by National Institutes of Health Grant MH-59811 to K. McKenna, F. Giuliano, and O. Rampin and a grant from Institut pour la Recherche sur la Moelle Epinière, 1996, to F. Giuliano and O. Rampin.

Part of the results was presented at the 28th Annual Meeting of the Society for Neuroscience, Los Angeles, 1998.

\section{REFERENCES}

1. Andersson KE and Wagner G. Physiology of penile erection. Physiol Rev 75: 191-236, 1995.

2. Anouar A, Clerget MS, Durroux T, Barberis C, and Germain G. Comparison of vasopressin and oxytocin receptors in the rat uterus and vascular tissue. Eur J Phamacol 308: 87-96, 1996.

3. Argiolas A and Melis MR. Neuromodulation of penile erection: an overview of the role of neurotransmitters and neuropeptides. Prog Neurobiol 47: 235-255, 1995.

4. Argiolas A, Melis MR, Mauri A, and Gessa GL. Paraventricular nucleus lesion prevents yawning and penile erection induced by apomorphine and oxytocin but not by ACTH in rats. Brain Res 421: 349-352, 1987.

5. Beckett SD, Hudson RS, Walker DF, Vachon RI, and Reynolds TM. Corpus cavernosum penis pressure and external penile muscle activity during erection in the goat. Biol Reprod 7: 359364, 1972.

6. Bernabé J, Rampin O, Sachs BD, and Giuliano F. Intracavernous pressure during erection in rats: an integrative approach based on telemetric recording. Am J Physiol Regulatory Integrative Comp Physiol 276: R441-R449, 1999.

7. Buijs RM. Intra- and extrahypothalamic vasopressin and oxytocin pathways in the rat. Pathways to the limbic system, medulla oblongata and spinal cord. Cell Tissue Res 192: 423-435, 1978.

8. Chen KK, Chan SH, Chang LS, and Chan JY. Participation of paraventricular nucleus of hypothalamus in central regulation of penile erection in the rat. $J$ Urol 158: 238-244, 1997.

9. DeGroat WC and Booth AM. Synaptic transmission in pelvic ganglia. In: The Autonomic Nevous System. Nervous Control of the Urogenital System, edited by Maggi CA. London: Harwood Academic, 1993, vol. 3, chapt. 9, p. 291-347.

10. Di Scala-Guenot D and Strosser MT. Downregulation of the oxytocin receptor on cultured astroglial cells. Am J Physiol Cell Physiol 268: C413-C418, 1995.

11. Einspanier A and Ivell R. Oxytocin and oxytocin receptor expression in reproductive tissues of the male marmoset monkey. Biol Reprod 56: 416-422, 1997.

12. Giuliano F, Bernabé J, Jardin A, and Rousseau JP. Antierectile role of the sympathetic nervous system in rats. $J$ Urol 150: 519-524, 1993.

13. Giuliano F, Rampin O, Bernabé J, and Rousseau JP. Neural control of penile erection in the rat. J Auton Nerv Syst 55: 36-44, 1995.

14. Hancock MB and Peveto CA. Preganglionic neurons in the sacral spinal cord of the rat: an HRP study. Neurosci Lett 11: $1-5,1979$.

15. Hosoya $\mathbf{Y}$ and Matsushita M. Identification and distribution of the spinal and hypophyseal projection neurons in the paraventricular nucleus of the rat. A light and electron microscopic study with the horseradish peroxidase method. Exp Brain Res 35: 315-331, 1979.

16. Liu YC, Salamone JD, and Sachs BD. Impaired sexual response after lesions of the paraventricular nucleus of the hypothalamus in male rats. Behav Neurosci 111: 1361-1367, 1997.

17. LoPachin RM, Rudy TA, and Yaksh TL. An improved method for chronic catheterization of the rat spinal subarachnoid space. Physiol Behav 27: 559-561, 1981.

18. Marson L, Platt KB, and McKenna KE. Central nervous system innervation of the penis as revealed by the transneuronal transport of pseudorabies virus. Neuroscience 55: 263$280,1993$.

19. Marson L and McKenna KE. CNS cell groups involved in the control of the ischiocavernosus and bulbospongiosus muscles: a transneuronal tracing study using pseudorabies virus. J Comp Neurol 374: 161-179, 1996.

20. Melin P. Effects in vivo of neurohypophysial hormones on the contractile activity of accessory sex organs in male rabbits. $J$ Reprod Fertil 22: 283-292, 1970.

21. Nadelhaft I and Booth AM. The location and morphology of preganglionic neurons and the distribution of visceral afferents from the rat pelvic nerve: a horseradish peroxidase study. J Comp Neurol 226: 238-245, 1984.

22. Pandita RK, Nylen A, and Andersson KE. Oxytocin-induced stimulation and inhibition of bladder activity in normal, conscious rats: influence of nitric oxide synthase inhibition. Neuroscience 85: 1113-1119, 1998.

23. Purohit RC and Beckett SD. Penile pressures and muscle activity associated with erection and ejaculation in the dog. Am J Physiol 231: 1343-1348, 1976.

24. Rampin O, Bernabé J, and Giuliano F. Spinal control of penile erection. World J Urol 15: 2-13, 1997.

25. Schmidt MH and Schmidt HS. The ischiocavernosus and bulbospongiosus muscles in mammalian penile rigidity. Sleep 16: 171-183, 1993.

26. Schmidt MH, Valatx JL, Sakai K, Debilly G, and Jouvet M. Corpus spongiosum penis pressure and perineal muscle activity during reflexive erections in the rat. Am $J$ Physiol Regulatory Integrative Comp Physiol 269: R904-R913, 1995. 
27. Sermasi E and Coote JH. Oxytocin acts at V1 receptors to excite sympathetic preganglionic neurones in neonate rat spinal cord in vitro. Brain Res 647: 323-332, 1994.

28. Steers WD, Mallory B, and DeGroat WC. Electrophysiological study of neural activity in penile nerve of the rat. Am $J$ Physiol Regulatory Integrative Comp Physiol 254: R989-R1000, 1988.

29. Swanson LW and McKellar S. The distribution of oxytocinand neurophysin-stained fibers in the spinal cord of the rat and monkey. J Comp Neurol 188: 87-106, 1979.

30. Tang Y, Rampin O, Calas A, Facchinetti P, and Giuliano F. Oxytocinergic and serotonergic innervation of identified lumbosacral nuclei controlling penile erection in the male rat. Neuroscience 82: 241-254, 1998 .

31. Tang Y, Rampin O, Giuliano F, and Ugolini G. Spinal and brain circuits to motoneurons of the bulbospongiosus muscle: retrograde transneuronal tracing with rabies virus. $J$ Comp Neurol 414: 167-192, 1999.
32. Tarhan F, Ersev D, Aslan N, Ozgul A, Kuyumcuoglu U, and Oktay S. Oxytocin-induced contractions of the rabbit corpus cavernosum. Eur Urol 28: 255-258, 1995.

33. Tribollet E, Barberis C, and Arsenijevic Y. Distribution of vasopressin and oxytocin receptors in the rat spinal cord: sexrelated differences and effects of castration in pudendal motor nuclei. Neuroscience 78: 499-509, 1997.

34. Veronneau-Longueville F, Rampin O, Freund-Mercier MJ, Tang Y, Calas A, Marson L, McKenna KE, Stoeckel ME, Benoit G, and Giuliano F. Oxytocinergic innervation of autonomic nuclei controlling penile erection in the rat. Neuroscience 93: 1437-1447, 1999.

35. Wagner CK, Sisk CL, and Clemens LG. Neurons in the paraventricular nucleus of the hypothalamus that project to the sexually dimorphic lower lumbar spinal cord concentrate ${ }^{3} \mathrm{H}$-estradiol in the male rat. $J$ Neuroendocrinol 5: 545-551, 1993.

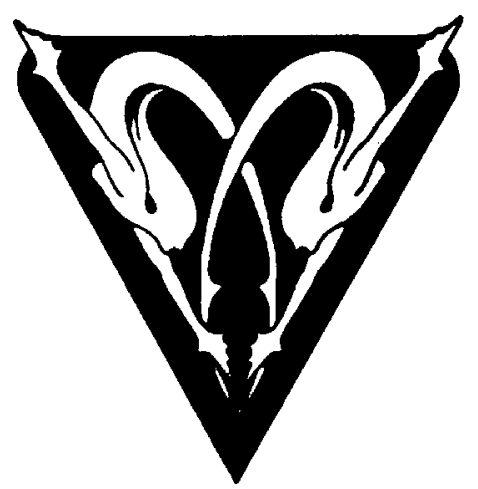

